\title{
Experimental Microemulsion Flooding Study to Increase Low Viscosity Oil Recovery Using Glass Micromodel
}

\author{
Hamed Hematpur $\mathbb{D D}^{1}$ Reza Abdollahi ${ }^{1},{ }^{1}$ Mohsen Safari-Beidokhti $\left(D^{1}{ }^{1}\right.$ \\ and Hamid Esfandyari $\mathbb{C}^{2}$ \\ ${ }^{1}$ EOR Research Department, Research Institute of Petroleum Industry, Tehran, Iran \\ ${ }^{2}$ Abadan Faculty of Petroleum Engineering, Petroleum University of Technology, Abadan, Iran \\ Correspondence should be addressed to Hamid Esfandyari; esfandyari_shirazu@yahoo.com
}

Received 19 May 2021; Accepted 4 September 2021; Published 13 September 2021

Academic Editor: Mohammad Yazdi

Copyright (C) 2021 Hamed Hematpur et al. This is an open access article distributed under the Creative Commons Attribution License, which permits unrestricted use, distribution, and reproduction in any medium, provided the original work is properly cited.

\begin{abstract}
The growing demand for clean energy can be met by improving the recovery of current resources. One of the effective methods in recovering the unswept reserves is chemical flooding. Microemulsion flooding is an alternative for surfactant flooding in a chemical-enhanced oil recovery method and can entirely sweep the remaining oil in porous media. The efficiency of microemulsion flooding is guaranteed through phase behavior analysis and customization regarding the actual field conditions. Reviewing the literature, there is a lack of experience that compared the macroscopic and microscopic efficiency of microemulsion flooding, especially in low viscous oil reservoirs. In the current study, one-quarter five-spot glass micromodel was implemented for investigating the effect of different parameters on microemulsion efficiency, including surfactant types, injection rate, and micromodel pattern. Image analysis techniques were applied to represent the phase saturations throughout the microemulsion flooding tests. The results confirm the appropriate efficiency of microemulsion flooding in improving the ultimate recovery. LABS microemulsion has the highest efficiency, and the increment of the injection rate has an adverse effect on oil recovery. According to the pore structure's tests, it seems that permeability has little impact on recovery. The results of this study can be used in enhanced oil recovery designs in low-viscosity oil fields. It shows the impact of crucial parameters in microemulsion flooding.
\end{abstract}

\section{Introduction}

The decreasing trend of fossil resources discovery in parallel with the expanding energy demand raises the eminence of techniques and approaches (reservoir-based and well-based) applied to improve the recovery of current resources [1-10]. Approximately, $70 \%$ of the reserves are not producible naturally [11-15]. This significant trapped reserve is an attractive target for applying enhanced oil recovery (EOR) methods [16-23].

Generally, EOR techniques are majorly categorized into thermal and nonthermal. The main subdivisions of nonthermal EOR are miscible and chemical techniques. Chemical EOR techniques refer to the application of standalone or combination of different materials (caustic, surfactant, polymer, and micellar/emulsion). These techniques substantially enhance the recovery by improving the mobility ratio or by decreasing the saturation of residual oil. Many parameters, including mineralogy, permeability, viscosity ranges, temperature, and salinity, affect the efficiency of chemical flooding [4, 24-28].

One of the effective chemical EOR methods is microemulsion flooding $[29,30]$. This method was first suggested as an alternative for surfactant flooding. It is more efficient in comparison to surfactants [30]. The microemulsion solution consists of three main components, including water, hydrocarbon, and surfactant. Two other components (cosurfactant and electrolyte) may be added to modify the solution according to the reservoir conditions. This multiphase microemulsion can be water external, oil external, or a three-phase solution consisting of water, hydrocarbon, and surfactant $[4,24,25]$. Theoretically, this method is capable of increasing the recovery up to $100 \%$. Microemulsions can remarkably induce the interfacial tension (IFT) to values of 
$10^{-2}-10^{-3} \mathrm{mN} \mathrm{m}^{-1}$. The IFT reduction arouses spontaneous emulsification and consequently unswept oil displacement [29]. The main detrimental phenomenon that affects the efficiency of microemulsion flooding is the retention of surfactant molecules on the reservoir rock. Other factors that affect microemulsion flooding include salinity and surfactant concentration [31-33].

Microemulsion can be flooded in two general approaches. First, the solution is prepared on the surface and then injected $[30,34]$. In the second method, the microemulsion is generated in the reservoir by continuous injection of surfactants [35]. Microemulsion flooding needs a high concentration of surfactants, and it is the main restricting factor for the field application of this technique [29, 36-38].

So far, many attempts have been made to investigate all prospects of microemulsion flooding. The equilibrium condition of microemulsion along the excess oil, water, or both was studied by Winsor [39]. Winsor categorized the microemulsion system into four types (Figure 1):

Type I systems are made of an oil-water microemulsion that coexists with an additional oil phase

Type II systems, an oil-water microemulsion, exist with an extra water phase

Type III systems, three discrete phases of microemulsion, water, and oil coexist together

Type IV systems, a homogeneous and single phase of microemulsion exists

Healy and Reed investigated some microemulsion fundamentals (IFT, salinity, and viscosity). They related the phase behavior results to Winsor's concepts [40]. Holm used sodium sulfonates to produce microemulsion for the EOR test and reported the effect of temperature on microemulsion efficiency [41]. Healy et al. conducted the microemulsion flooding (with the addition of monoethanolamine salt of alkylorthoxylene sulfonic acid) and stated the impact of surfactant retention on the reservoir rock [42]. The influence of water salinity on surfactant retention and the consequent phase behavior was studied by Glover et al. [31]. Verkruyse and Salter showed that although the microemulsion (with the addition of ethoxylated alcohols) could considerably reduce the IFT, the ultimate recovery was not changed remarkably [43]. Bouabboune et al. compared surfactant with microemulsion flooding (alkali surfactant NM as a surfactant) and concluded that the microemulsion had a better performance [44]. Mandal et al. utilized the nanoemulsion in the EOR process (with the addition of Tergitol), and they found that this solution can improve the ultimate recovery by more than 30\% [45]. Karambeigi et al. studied the phase behavior of different solutions (including surfactant brine, biodiesel, and cosolvent) and the consequent efficiencies in carbonated rock [46]. Hu et al. used nanoparticles (iron oxide) for microemulsion and evaluated their application in EOR. They reported that this system significantly increased the oil recovery reaching $28.9 \%$ and presented a more stable pressure profile [47]. Ferreira et al. prepared microemulsion with

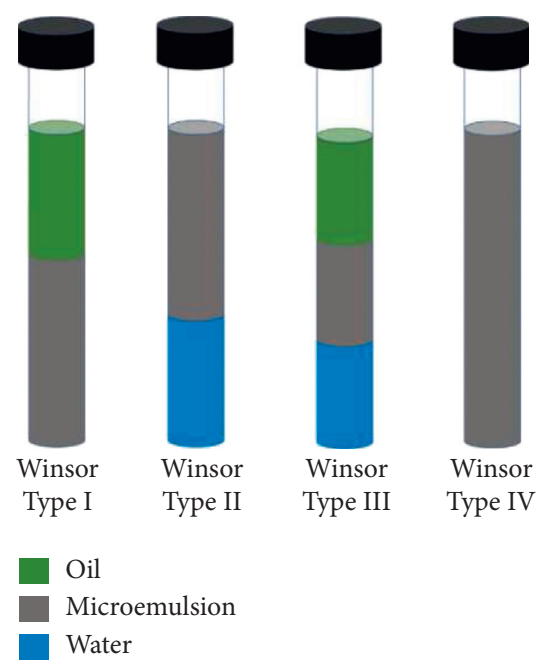

Figure 1: Classified microemulsion systems by Winsor [39].

glycerin, and the prepared solution was injected in a sandstone rock. The maximum attained recovery in this system was 49\% [48]. Castro Dantas et al. examined the effect of acid microemulsion on EOR in carbonate reservoirs, and the maximum reported recovery was 30\% [49].

One of the main methods that have been widely used for visualizing chemical flooding is the micromodel. This setup consists of an etched flow pattern that is visible by a microscope. The pattern can be synthetic or extracted from a real pore stricter. The visualization of fluid flow is very constructive in understanding the mechanism of the EOR process at the pore level. However, the visual micromodel encounters many limitations. The most important one is the difference in the flow pattern in the micromodel and field porous media [50-56]. It can be mentioned that few studies have been appropriately applied to quantify microemulsion flooding in micromodel experiments.

In this study, the one-quarter five-spot glass micromodel was used to investigate the effect of different factors including, solution injection rate, types of solution, and micromodel structure, on the performance of microemulsion flooding. In the end, they compared with each other to suggest the best conditions for one of the low viscous Iranian oil reservoirs.

\section{Experimental Setup and Procedure}

2.1. Low-Pressure Micromodel Apparatus. Figure 2 shows the micromodel setup used for microemulsion flooding in this study. All experiments were conducted at atmospheric pressure.

Six microemulsion flooding tests were performed to study the impact of the following parameters:

\section{Microemulsion type}

Injection rate

Pore structure

For each microemulsion flooding experiment, the following steps were repeated. 


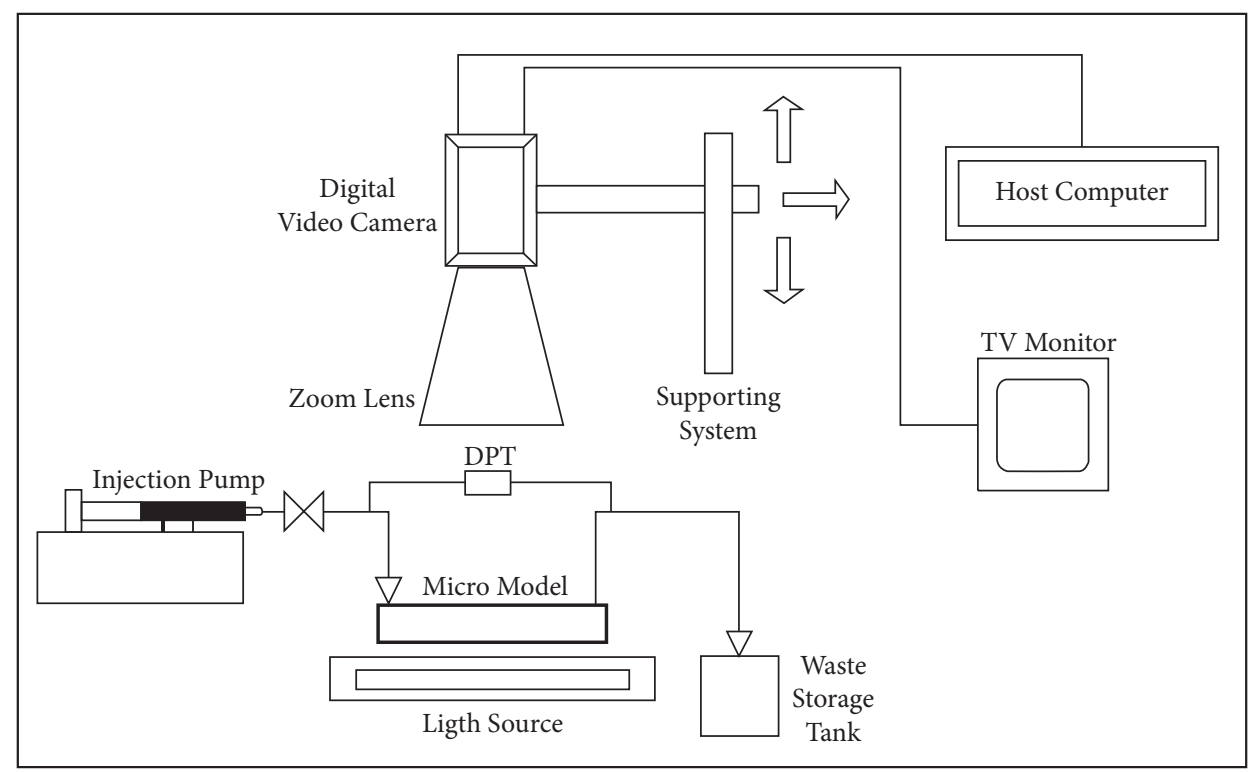

Figure 2: Schematic of micromodel assembly.

The first step was the saturation of the micromodel with brine. The saturated media was then flooded by oil to reach the initial water saturation. The saturated micromodel was kept for two weeks to restore wettability. Finally, the microemulsion was injected into the micromodel at a constant rate. The recoveries were recorded throughout the flooding process. The microscope of the zooming range of $200 \mathrm{X}$ to $500 \mathrm{X}$ was used to take pictures of high resolution to observe oil, connate water, solvent saturation, and asphaltene deposition after each experiment.

2.2. Crude Oil Properties. Experiments were conducted on the low viscous oil samples prepared from an Iranian oil field. The oil properties are represented in Table 1.

2.3. Synthetic Brine. Regarding the composition and properties of real field water samples, the synthetic brine (136000 ppm) with the following composition was prepared (Table 2).

2.4. Cleaning Fluid. Before conducting each experiment, the micromodel was sequentially washed with the injection of toluene, alcohol, and distilled water.

2.5. Microemulsion. Two solutions were prepared for investigating the efficiency of microemulsion in EOR improvement. The coconut fatty acid diethanolamide (cocamide DEA) [57] and linear alkylbenzenes (LABS) were used as surfactant and n-hexane as a hydrocarbon. The critical micelle concentration (CMC) of these two surfactants is $1.4 \% \mathrm{w} / \mathrm{w}$ and $0.65 \% \mathrm{w} / \mathrm{w}$, respectively. Figure 3 represents the structure of these surfactants.

To construct the ternary phase diagram, different concentrations (volume percent) of brine, surfactant, and n-hexane are mixed. The volume measurements were done primarily on a mass scale, considering the density of the
TABle 1: Oil properties.

\begin{tabular}{lcc}
\hline \multicolumn{3}{c}{ Temperature: $119^{\circ} \mathrm{C}$} \\
\hline Bubble point pressure (psia) & API & Viscosity (cp) \\
1959.7 & 43.6 & 0.554 \\
\hline
\end{tabular}

TABLE 2: Synthetic brine composition (136000 ppm).

\begin{tabular}{lcc}
\hline Component & Molecular weight $(\mathrm{g} / \mathrm{mol})$ & Concentration (g/lit) \\
\hline $\mathrm{MgCl}_{2} \cdot 6 \mathrm{H}_{2} \mathrm{O}$ & 203.3 & 1 \\
$\mathrm{CaCl}_{2} \cdot 2 \mathrm{H}_{2} \mathrm{O}$ & 147.03 & 3 \\
$\mathrm{Na}_{2} \mathrm{SO}_{4}$ & 142.04 & 30 \\
$\mathrm{NaCl}$ & 58.44 & 102 \\
\hline
\end{tabular}

components at the desired temperature. Different phases (Winsor microemulsion types) are recorded, and consequently, the ternary diagram is plotted considering the phases and volumes. Since the salinity of brine is fixed for injection (produced formation water), the sensitivity on salinity is not in the scope of this study.

The phase diagram of microemulsion containing cocamide DEA is given in Figure 4.

This solution has different behaviors in comparison to the ideal behavior presented by Green and Willhite [58]. It included several multiphase and single-phase regions. The volume percent of each component was estimated regarding the single-phase behavior of microemulsion.

Hadi et al. applied the cocamide DEA emulsion for heavy oil [57]. For light oil with high water saturation, it is better to apply a new microemulsion. In the second microemulsion, similar to Hadi's study [57], n-hexane was used as hydrocarbon, but LABS as surfactant.

Several titrations were done to obtain the phase behavior of LABS. As shown in Figure 5, the result was closer to the ideal behavior in comparison to the previous microemulsion. Also, laboratory pictures from results of one, two, and three phases are given in this figure. 
<smiles>CCCCCCCCCCCC(=O)N(CCO)CCO</smiles>

(a)

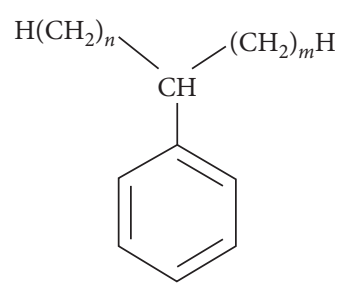

(b)

FIgURE 3: The chemical structure of cocamide DEA and LABS. (a) Cocamide DEA. (b) LABS.

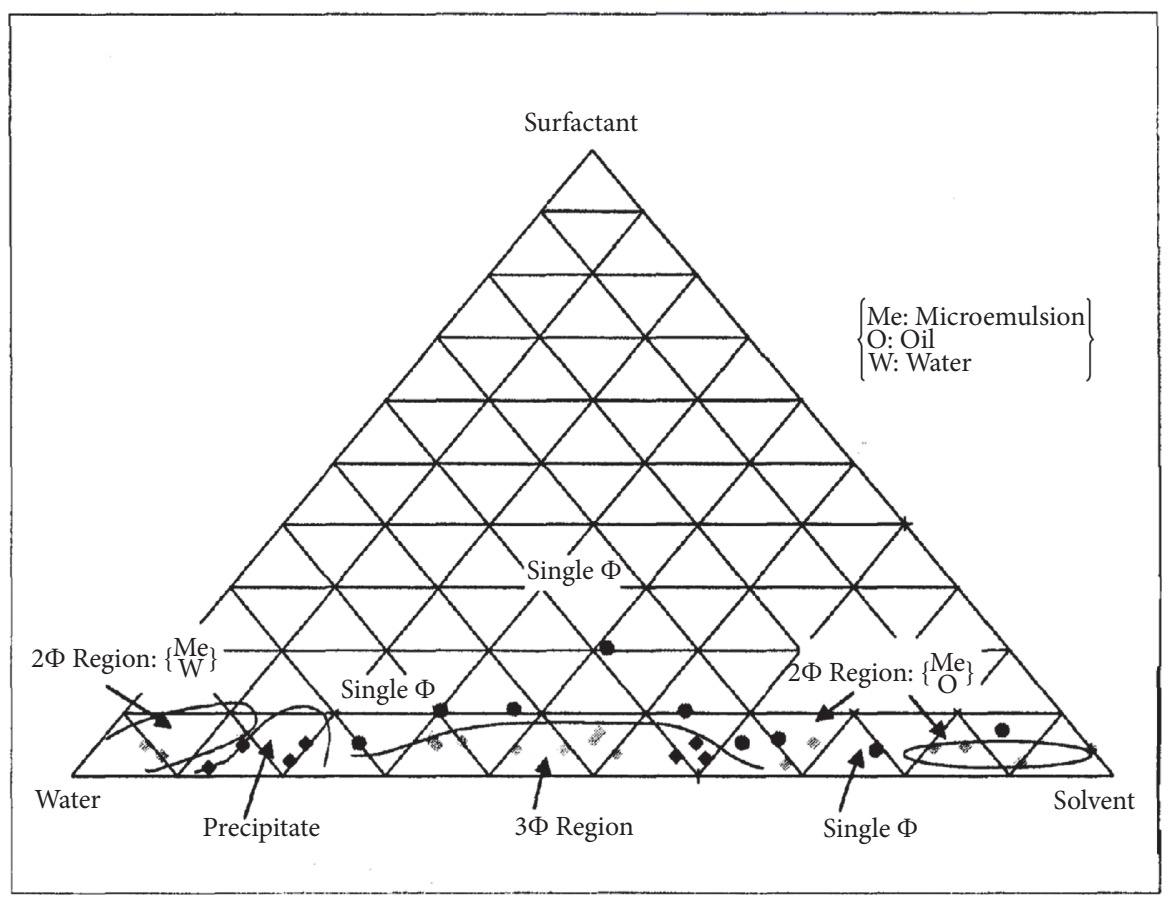

Figure 4: Ternary diagram for cocamide DEA [57].

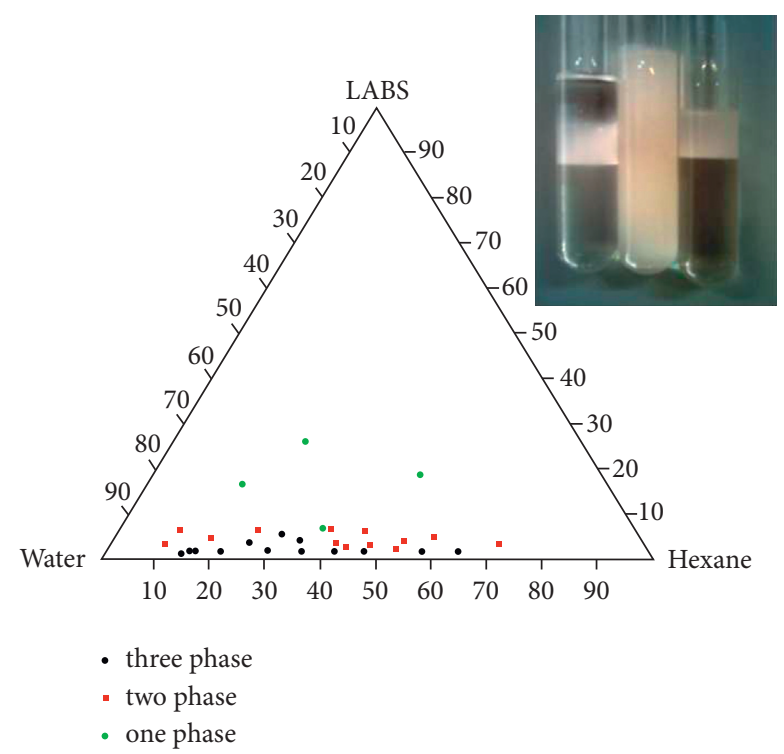

Figure 5: The ternary diagram for LABS. 
The final compositions chosen for injection are given in Table 3. The composition and the volume percentage of constitute materials were selected regarding the following criteria:

\section{Single-phase behavior \\ Minimum possible surfactant concentration (economic criterion) \\ Desirable viscosity}

2.6. Pattern Design. In this study, two synthetic hexagonal patterns with different coordination numbers and pore throat ratios were used for microemilsion tests. The patterns are shown in Figures 6 and 7 (the permeability of A and B patterns are 1500 and $2000 \mathrm{md}$, respectively).

Each pattern (with $6.5 * 6.5 \mathrm{~cm}$ area) was etched on a thick float plate (dimensions: $4 * 7 * 0.183$ inches) and covered with the same size plate. The cover had two ports for fluid injection and production (with $3 \mathrm{~mm}$ diameter). The etched and cover plates were connected and sealed to form an enclosed pore space.

\section{Result and Discussion}

3.1. Effect of Microemulsion Type. Pattern B was used to evaluate the efficiencies of suggested microemulsions. The injection rate of microemulsion into the saturated micromodel was $0.0008 \mathrm{cc} / \mathrm{min}$. Microemulsion A consists of hexane (hydrocarbon), LABS (surfactant), and brine. Microemulsion $B$ consists of hexane (hydrocarbon), coconut fatty acid diethanolamide (surfactant), and brine. The main mechanism for the recovery improvement is the reduction of IFT. Once the microemulsion front reaches the remained oil, it lowers the IFT, and consequently, the capillary force decreases. Capillary force plays an important role in phase trapping through the porous media, and reduction in capillary force leads to higher recovery. Viscous force is another force that plays a role in hydrocarbon recovery. Increasing the viscosity of injection fluid (lower mobility ratio) improves the recovery factor. Results show that type A has better efficiency than type B due to more IFT reduction and more elevated viscosity. However, this difference is not significant after $1 \mathrm{PV}$ of injection. The main difference between these two microemulsions is breakthrough time. Type B shows a higher breakthrough time (0.93 PV) in comparison to type A (0.31 PV) because it has a higher amount of hydrocarbon than type A. It seems that the increase of hydrocarbon concentration in microemulsion ascends the breakthrough time. However, the increase of breakthrough time does not affect the ultimate recovery significantly.

Figure 8 illustrates recoveries vs. the number of pore volume injections. According to this figure, it can be concluded that microemulsion A has a higher recovery than type B. Furthermore, type A has lower hydrocarbon content, and it can be the advantage of this type.

3.2. Effect of Injection Rate. In order to investigate the effect of injection rate on ultimate recovery, two different rates $(0.0008$ and $0.001 \mathrm{cc} / \mathrm{min})$ were tested. Pattern B and microemulsion type A were selected for these experiments, and other conditions were the same as before. The results show that breakthrough is highly dependent on the rate of injection. In the case of changing the injection rate, the viscous force plays the main role. Increasing the injections' rate leads to a higher probability of viscous fingering throughout the flooding period. The viscous fingering brings the earlier breakthrough and lower recovery. This analysis is based on the pore volume of the injected microemulsion, not on the time of injection. Comparing the breakthrough according to the time of injection might be inaccurate. The breakthrough time for 0.0008 and $0.001 \mathrm{cc} / \mathrm{min}$ is 0.31 and $0.26 \mathrm{PV}$, respectively.

Figure 9 shows that, by increasing the injection rate, the recovery goes down. In addition, the graph shows that changing the injection rate does not have a sensible effect on the trend of the chart, and both scenarios have the same trend.

3.3. Effect of Pore Structure. Two patterns A and B, with different permeabilities, were used for evaluating the impact of flow networks on ultimate recovery of microemulsion flooding. Microemulsion type A with $0.0008 \mathrm{cc} / \mathrm{min}$ rate was injected in these tests. Figure 10 illustrates the effect of the pore structure and permeability on the consequent recovery. The permeability variation affects the viscous forces, so the IFT reduction mechanism for both cases is the same. However, the results showed that there was no obvious change in recovery by changing the permeability. Roughly two graphs in Figure 10 are the same. Since the IFT reduction is the main mechanism for microemulsion flooding and leads to a high recovery factor (about $80 \%$ in our study), the impact of permeability on the ultimate recovery can be negligible in high recovery factor values.

3.4. Qualitative Observation of Connate Water's Effect. Qualitative microscopic observations were conducted throughout the flooding period of each test. Figure 11 illustrates six stages of microemulsion (A) flooding in pattern A. The figure clearly shows the movement of connate water in the frontal path; also, it shows that the front moves very stable and sweeps all water and oil through its way. The highviscosity and low-mobility ratio of microemulsion causes the front stability in this case. Figure 12 shows six stages of flooding with microemulsion (B). It shows that the front is not very stable, and viscous fingering occurs to some extent. The lower viscosity of this microemulsion is the reason for this behavior.

Figures 13 and 14 show the microscopic images to illustrate the mechanism of the connate water (trapped or made the film on grain) discharging during the microemulsion flooding.

Figure 13 shows when the microemulsion faces the connate water, the microemulsion causes IFT reduction, and consequently, connate water becomes movable. The water which is not in touch with the microemulsion cannot move easily because of high interfacial tension. Figure 14 depicts 
Table 3: Composition of microemulsions.

\begin{tabular}{lccccc}
\hline Composition & Surfactant & $\begin{array}{c}\text { Surfactant } \\
\text { vol. (\%) }\end{array}$ & $\begin{array}{c}\text { n-Hexane } \\
\text { vol. (\%) }\end{array}$ & $\begin{array}{c}\text { Water } \\
\text { vol. (\%) }\end{array}$ & $\begin{array}{c}\text { Viscosity (cp) } \\
\text { Microemulsion (A) }\end{array}$ \\
Microemulsion (B) & LABS & 6.7 & 56.1 & 37 & 8 \\
\hline
\end{tabular}

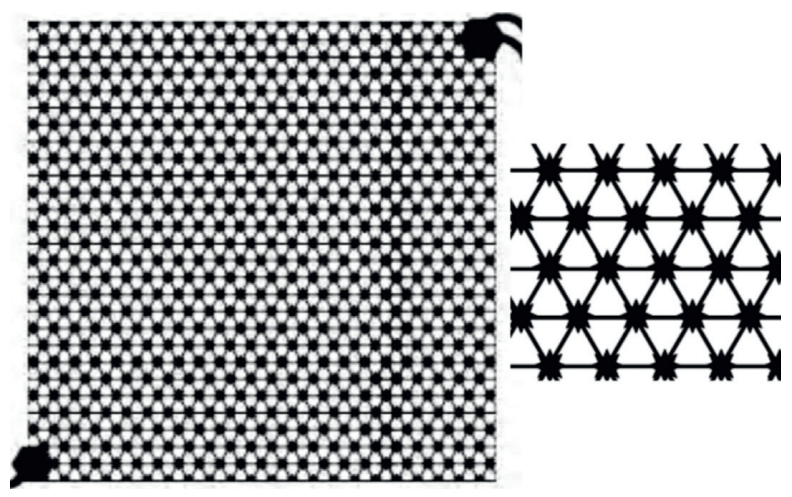

Figure 6: Triple hexagonal pattern (A) with the coordination number of 6 and pore-throat ratio of 4 .

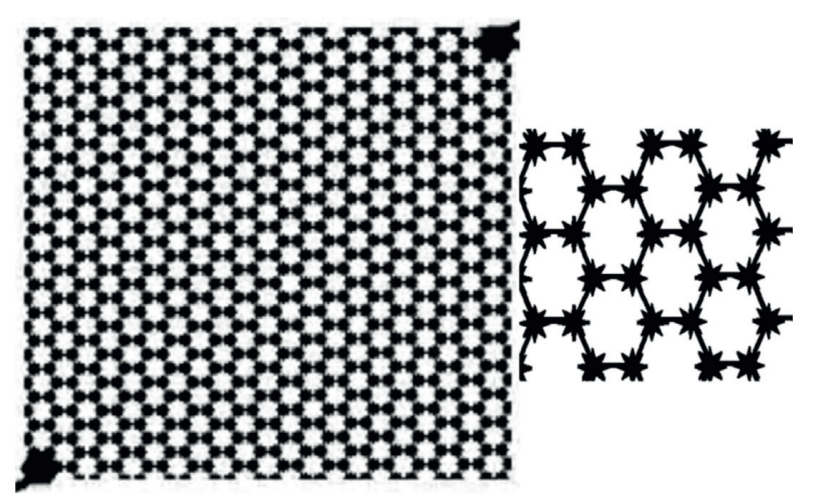

FIgURE 7: Single hexagonal pattern (B) with the coordination number of 3 and pore-throat ratio of 6 .

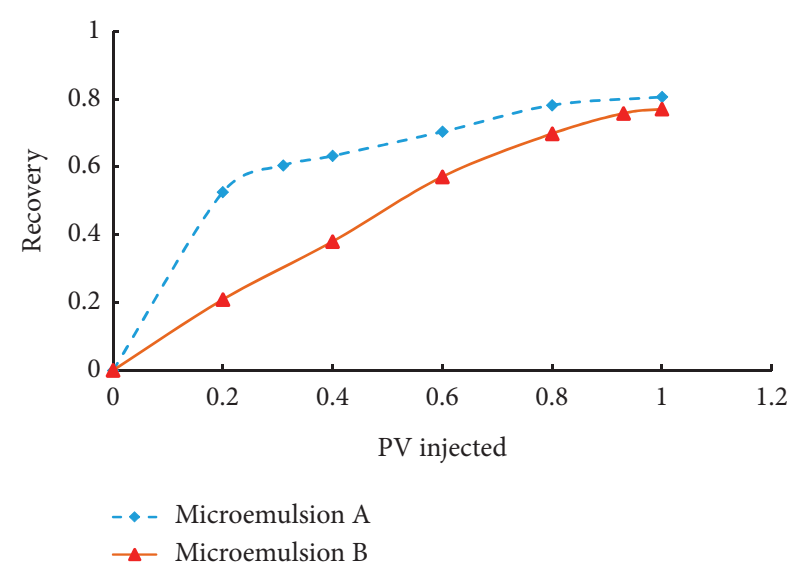

FIGURE 8: Effect of microemulsion types on recovery.

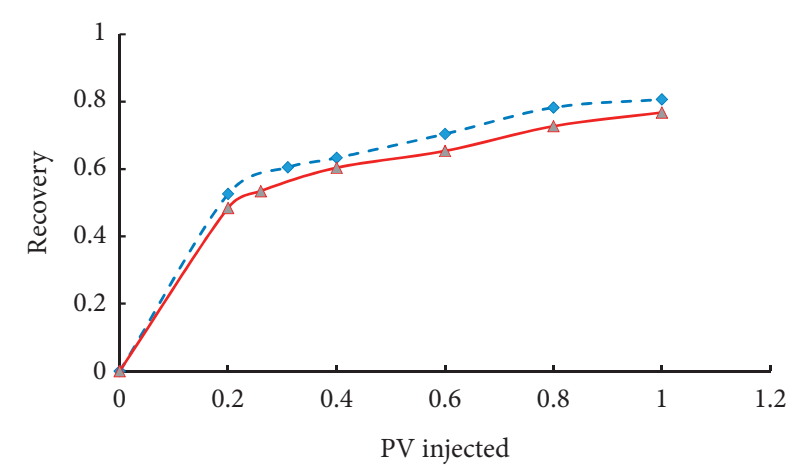

$-0.0008 \mathrm{cc} / \mathrm{min}$

$\rightarrow 0.001 \mathrm{cc} / \mathrm{min}$

Figure 9: Effect of the injection rate on recovery.

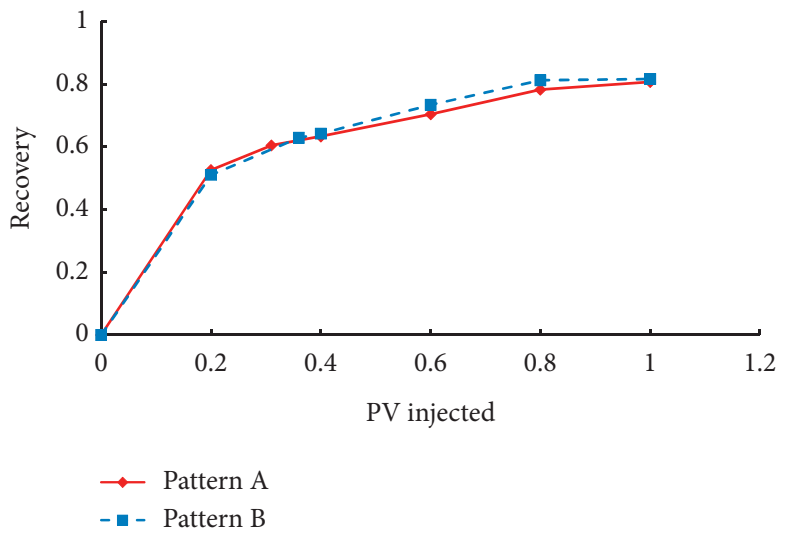

FIGURE 10: Effect of pore structure on oil recovery in the microemulsion flooding. 
$\mathrm{PV}=0.2$

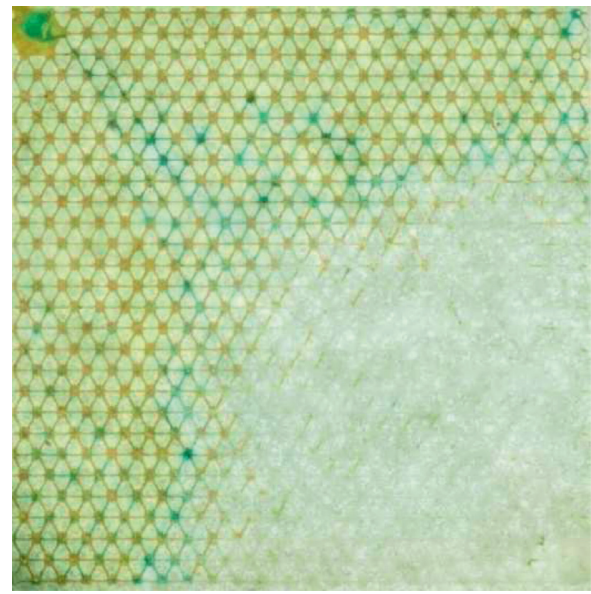

$\mathrm{PV}=0.4$

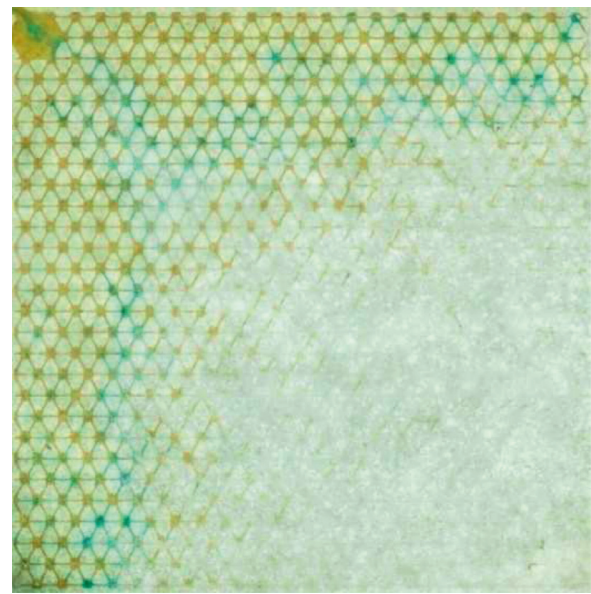

$\mathrm{PV}=0.8$

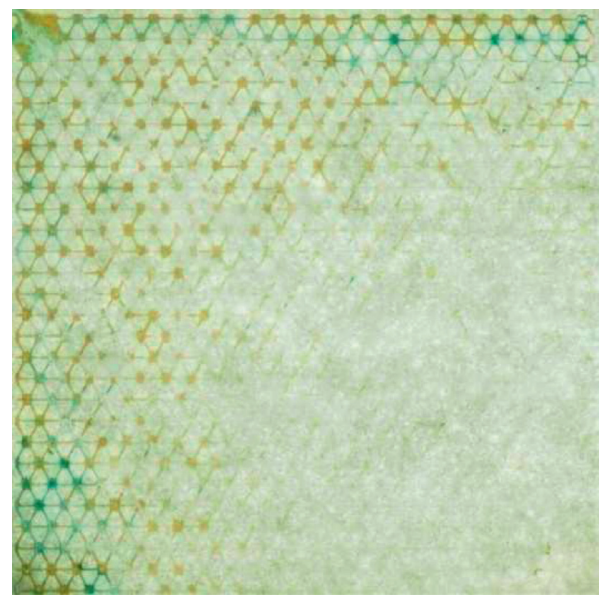

$\mathrm{PV}=0.31(\mathrm{BT})$

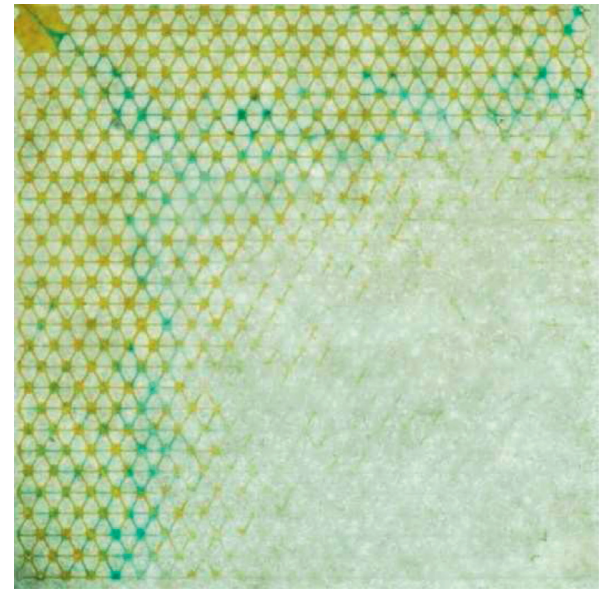

$\mathrm{PV}=0.6$

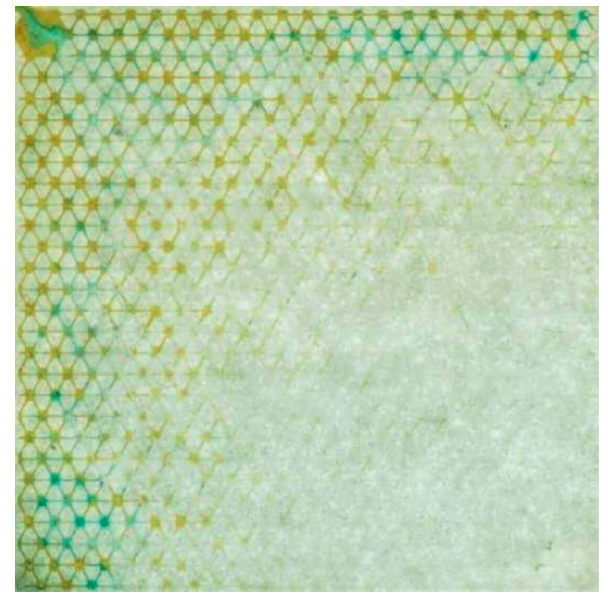

$\mathrm{PV}=1$

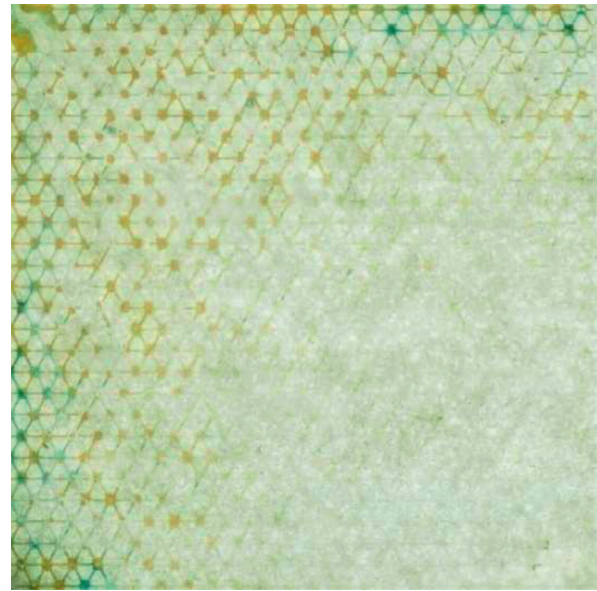

FIgURE 11: 6-stages of microemulsion flooding (A) (green: water, light brown: oil, and white: emulsion). 
$\mathrm{PV}=0.2$

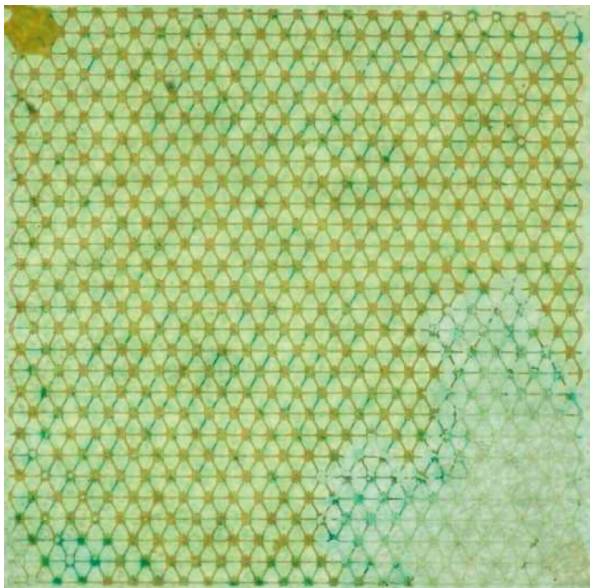

$\mathrm{PV}=0.4$

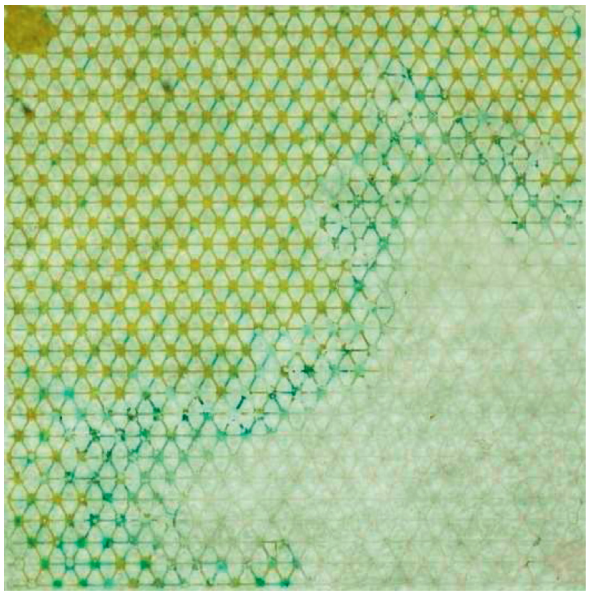

$\mathrm{PV}=0.93(\mathrm{BT})$

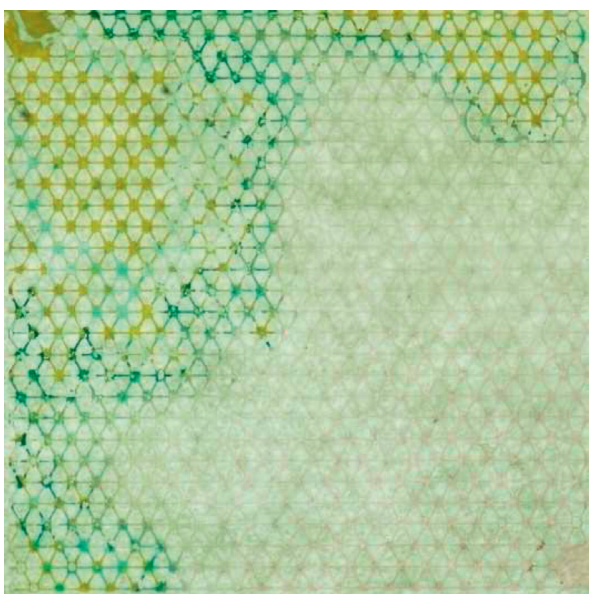

$\mathrm{PV}=0.4$

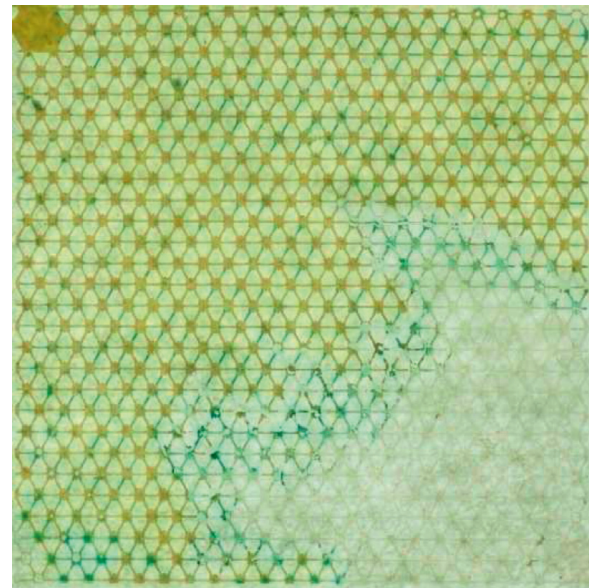

$\mathrm{PV}=0.6$

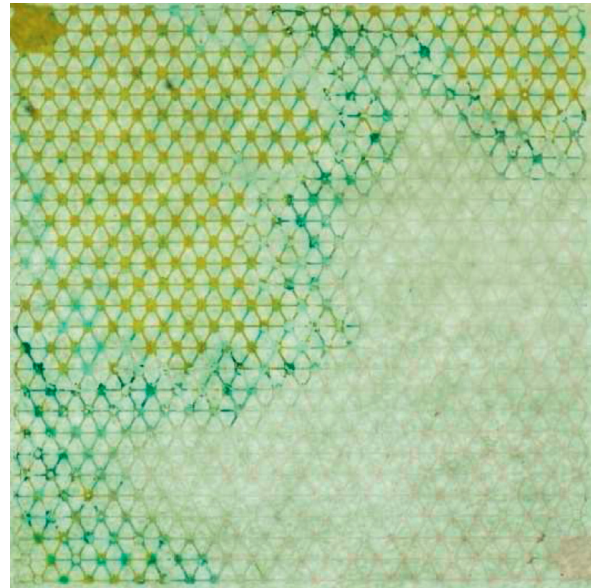

$\mathrm{PV}=1$

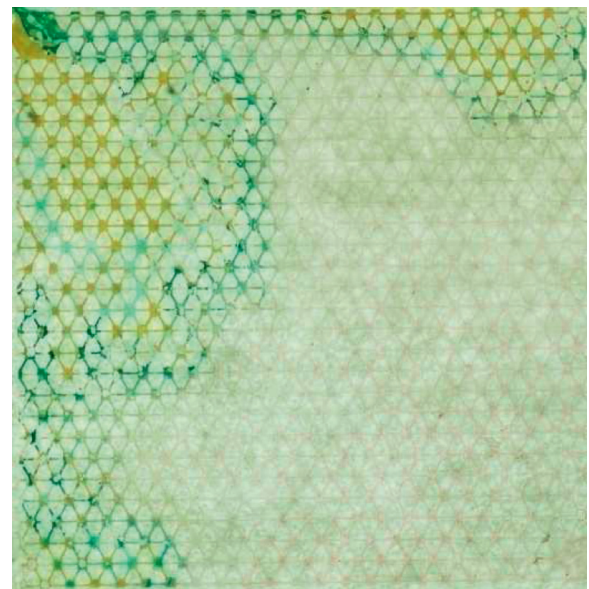

FIGURE 12: 6-stages of microemulsion flooding (B) (green: water, light brown: oil, and white: emulsion).

this state. In this pore, microemulsion does not reach the connate water.

These experiments show how microemulsion affects the water saturation in two sides of microemulsion front.
Behind the front, the microemulsion changes the endpoint of the residual water saturation by reducing the IFT value. Consequently, the swept water is moved to the head of the front. 

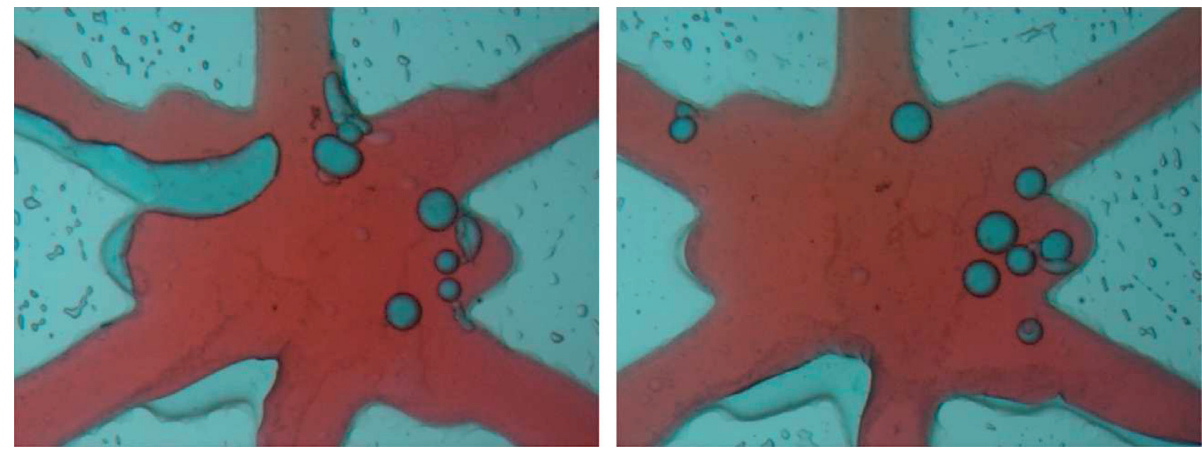

FIGURE 13: Demonstration of connate water discharging by microemulsion.
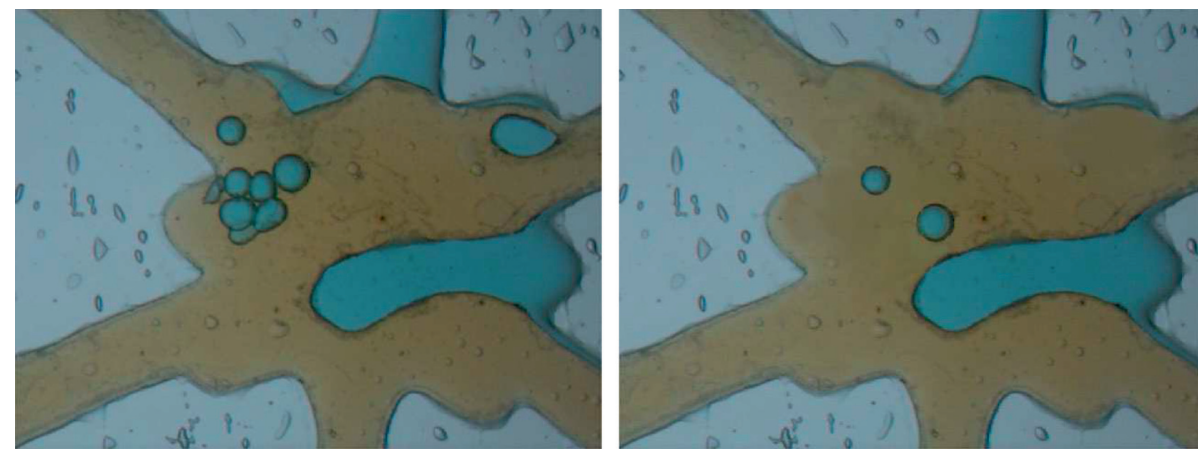

FIGURE 14: Origin zone, which was not in touch with microemulsion.

\section{Conclusion}

Regarding the objectives of this study, the following conclusions were obtained:

This study investigates the application of microemulsion flooding for low viscosity oil. The microemulsion flooding leads to interfacial tension reduction and consequently increasing oil recovery.

Two types of surfactants were used in this study. The results show that the type of surfactant has a significant effect on the recovery factor. The LABS surfactant increases the recovery by two times after $0.2 \mathrm{PV}$ injection.

In the case of injection rates, increasing the rate from 0.0008 to $0.001 \mathrm{cc} / \mathrm{min}$ leads to a slight increase in oil recovery.

The permeability is another parameter that was studied using different pore structures. The pore structure does not show a sensible effect on recovery.

Behind the front of the microemulsion, the end-point saturations are changed due to changing of IFT.

\section{Data Availability}

The data used to support the findings of this study are included within the article.

\section{Conflicts of Interest}

The authors declare no conflicts of interest.

\section{References}

[1] Y. Chen, H. Wang, Y. Wang, and G. Ma, "Numerical evaluation of a fracture acidizing treatment in a three-dimensional fractured carbonate reservoir," Journal of Natural Gas Science and Engineering, vol. 81, 2020.

[2] X. Zhuang, S. Zhou, M. Sheng, and G. Li, "On the hydraulic fracturing in naturally-layered porous media using the phase field method," The Engineering Geologist, vol. 266, 2020.

[3] O. Massarweh and A. S. Abushaikha, "The use of surfactants in enhanced oil recovery: a review of recent advances," Energy Report, vol. 6, 2020.

[4] H. K. van Poollen, Fundamentals of Enhanced Oil Recovery, PenWell Books, Tulsa, OK, USA, 1980.

[5] R. Abdollahi and S. R. Shadizadeh, "The effect of spent acid on carbonate rock wettability during a matrix acidizing treatment," Petroleum Science and Technology, vol. 32, 2014.

[6] R. Abdollahi, H. Esfandyari, M. Nadri Pari, and A. Davarpanah, "Conventional diverting techniques and novel fibr-assisted self-diverting system in carbonate reservoir acidizing with successful case studies," Petroleum Research, 2021, In press.

[7] R. Abdollahi, M. Nadri, H. Gholghanddashti, M. Safari, and M. Zare Reisabadi, "A stepwise approach for identification of water production mechanisms in gas reservoirs," Energy Sources, Part A: Recovery, Utilization, and Environmental Effects, 2021, In press.

[8] H. Esfandyari, S. R. Shadizadeh, F. Esmaeilzadeh, and A. Davarpanah, "Implications of anionic and natural surfactants to measure wettability alteration in EOR processes," Fuel, vol. 278, 2020.

[9] H. Hematpour, R. Arabjamloei, M. Nematzadeh, H. Esmaili, and M. Mardi, "An experimental investigation of surfactant 
flooding efficiency in low viscosity oil using a glass micromodel," Energy Sources, Part A: Recovery, Utilization, and Environmental Effects, vol. 34, 2012.

[10] M. Yazdi, N. A. Golilarz, A. Nedjati, and K. A. Adesina, “An improved lasso regression model for evaluating the efficiency of intervention actions in a system reliability analysis," Neural Computing \& Applications, vol. 33, pp. 7913-7928, 2021.

[11] X. Hu, M. Li, C. Peng, and A. Davarpanah, "Hybrid thermalchemical enhanced oil recovery methods; an experimental study for tight reservoirs," Symmetry (Basel), vol. 12, 2020.

[12] S. Nesic, A. Zolotukhin, V. Mitrovic, D. Govedarica, and A. Davarpanah, "An analytical model to predict the effects of suspended solids in injected water on the oil displacement efficiency during waterflooding," Processes, vol. 8, 2020.

[13] J. C. S. Rosestolato, A. Pérez-Gramatges, E. R. Lachter, and R. S. V. Nascimento, "Lipid nanostructures as surfactant carriers for enhanced oil recovery," Fuel, vol. 239, 2019.

[14] N. Saxena, A. Saxena, and A. Mandal, "Synthesis, characterization and enhanced oil recovery potential analysis through simulation of a natural anionic surfactant," Journal of Molecular Liquids, vol. 282, 2019.

[15] H. Esfandyari, A. Haghighat Hoseini, S. R. Shadizadeh, and A. Davarpanah, "Simultaneous evaluation of capillary pressure and wettability alteration based on the USBM and imbibition tests on carbonate minerals," Journal of Petroleum Science and Engineering, vol. 200, no. 12, 2020.

[16] Y. A. Alzahid, P. Mostaghimi, S. D. C. Walsh, and R. T. Armstrong, "Flow regimes during surfactant flooding: the influence of phase behaviour," Fuel, vol. 236, 2019.

[17] V. Alvarado and E. Manrique, "Enhanced oil recovery: an update review," Energies, vol. 3, 2010.

[18] A. Barati-Harooni, A. Najafi-Marghmaleki, A. Tatar, and A. H. Mohammadi, "Experimental and modeling studies on adsorption of a nonionic surfactant on sandstone minerals in enhanced oil recovery process with surfactant flooding," Journal of Molecular Liquids, vol. 220, 2016.

[19] H. Esfandyari, A. Moghani, F. Esmaeilzadeh, and A. Davarpanah, "A laboratory approach to measure carbonate rocks' adsorption density by surfactant and polymer," Mathematical Problems in Engineering, vol. 2021, Article ID 5539245, 7 pages, 2021.

[20] R. Eghbali, P. Khanmohammadi Hazaveh, F. Rashchi, and A. Ataie, "Recovery of manganese from a low-grade waste and valorization via the synthesis of a nanostructured magnetic manganese ferrite," Materials Science and Engineering: B, vol. 269, Article ID 115177, 2021.

[21] F. Pan, Z. Zhang, X. Zhang, and A. Davarpanah, "Impact of anionic and cationic surfactants interfacial tension on the oil recovery enhancement," Powder Technology, vol. 373, 2020.

[22] H. Hematpour, M. Mardi, S. Edalatkhah, and R. Arabjamaloei, "Experimental study of polymer flooding in low-viscosity oil using one-quarter five-spot glass micromodel," Petroleum Science and Technology, vol. 29, 2011.

[23] M. R. SaharKafashi, E. Eshraghi, L. Kuhar, A. Bona, and N. Aleksandar, "Visual study of TiO2 nanofluid stabilization methods on inhibition of asphaltene precipitation in porous media," Minerals Engineering, vol. 169, Article ID 106953, 2021.

[24] S. Kafashi, M.-R. Rasaei, and G. R. Karimi, "Experimental study of nanoclay absorbents and additives' effects on modification of rheological properties of drilling fluids in porous media using glass micromodel," Journal of Porous Media, vol. 23, no. 6, pp. 627-639, 2020.
[25] S. Thomas, "Enhanced oil recovery-an overview," Oil and Gas Science and Technology, vol. 63, no. 1, pp. 9-19, 2008.

[26] N. Hadian Nasr, S. M. Mahmood, and H. Hematpur, "A rigorous approach to analyze bulk and coreflood foam screening tests," Journal of Petroleum Exploration and Production Technology, vol. 9, 2019.

[27] H. Hematpour, S. M. Mahmood, N. H. Nasr, M. Karimi, and M. Bataee, "Experimental investigation on the mobility reduction factor of surfactant-alternating-gas foam flooding," Kuwait Journal of Science, vol. 46, 2019.

[28] H. Hematpur, S. M. Mahmood, N. H. Nasr, and K. A. Elraies, "Foam flow in porous media: concepts, models and challenges," Journal of Natural Gas Science and Engineering, vol. 53, 2018.

[29] A. Bera, T. Kumar, K. Ojha, and A. Mandal, "Screening of microemulsion properties for application in enhanced oil recovery," Fuel, vol. 121, 2014.

[30] V. C. Santanna, F. D. S. Curbelo, T. N. Castro Dantas, A. A. Dantas Neto, H. S. Albuquerque, and A. I. C. Garnica, "Microemulsion flooding for enhanced oil recovery," Journal of Petroleum Science and Engineering, vol. 66, 2009.

[31] C. J. Glover, M. C. Puerto, J. M. Maerker, and E. L. Sandvik, "Surfactant phase behavior and retention in porous media," Society of Petroleum Engineers of AIME Journal, vol. 19, 1979.

[32] F. D. S. Curbelo, V. C. Santanna, E. L. B. Neto et al., "Adsorption of nonionic surfactants in sandstones," Colloids and Surfaces A: Physicochemical and Engineering Aspects, vol. 293, 2007.

[33] A. S. Zelenev, L. M. Champagne, and M. Hamilton, "Investigation of interactions of diluted microemulsions with shale rock and sand by adsorption and wettability measurements," Colloids and Surfaces A: Physicochemical and Engineering Aspects, vol. 391, 2011.

[34] M. Safari-Beidokhti, A. Hashemi, R. Abdollahi, H. Hematpur, and E. Hamid, "Numerical well test analysis of condensate dropout effects in dual-permeability model of naturally fractured gas condensate reservoirs: case studies in the south of Iran," Mathematical Problems in Engineering, vol. 2021, Article ID 9916914, 10 pages, 2021.

[35] A. A. Roozshenas, H. Hematpur, R. Abdollahi, and E. Hamid, "Water production problem in gas reservoirs: concepts, challenges, and practical solutions," Mathematical Problems in Engineering, vol. 2021, Article ID 9075560, 20 pages, 2021.

[36] V. C. Santanna, A. C. M. Silva, H. M. Lopes, and F. A. Sampaio Neto, "Microemulsion flow in porous medium for enhanced oil recovery," Journal of Petroleum Science and Engineering, vol. 105, 2013.

[37] M. F. Nazar, S. S. Shah, and M. A. Khosa, "Microemulsions in enhanced oil recovery: a review," Petroleum Science and Technology, vol. 29, 2011.

[38] P. Kamranfar and M. Jamialahmadi, "Effect of surfactant micelle shape transition on the microemulsion viscosity and its application in enhanced oil recovery processes," Journal of Molecular Liquids, vol. 198, 2014.

[39] C. Stubenrauch, Microemulsions: Background, New Concepts, Applications, Perspectives, Wiley, Hoboken, NJ, USA, 2009.

[40] R. L. Reed and R. N. Healy, Some Physicochemical Aspects of Microemulsion Flooding: A Review in: Improved Oil Recover by Surfactant Polymer Flooding, Academic Press, Cambridge, MA, USA, 1977.

[41] L. W. Holm, "Use of soluble oils for oil recovery," Journal of Petroleum Technology, vol. 23, 1971. 
[42] R. N. Healy, R. L. Reed, and C. W. Carpenter, "Laboratory study of microemulsion flooding," Society of Petroleum Engineers of AIME Journal, vol. 15, 1975.

[43] L. A. Verkruyse and S. J. Salter, "Potential use of nonionic surfactants in micellar flooding," in Proceedings of the SPE Oilfield and Geothermal Chemistry Symposium, Phoenix, Arizona, April 1985.

[44] M. Bouabboune, N. Hammouch, and S. Benhadid, "Comparision between micro-emulsion and surfactant solution flooding effeciency for enhanced oil recovery in tinfouyé oil field," in Proceedings of the Canadian International Petroleum Conference, Calgary, Alberta, June 2006.

[45] A. Mandal, A. Bera, K. Ojha, and T. Kumar, "Characterization of surfactant stabilized nanoemulsion and its use in enhanced oil recovery," in Proceedings of the SPE International Oilfield Nanotechnology Conference and Exhibition, Noordwijk, The Netherlands, June 2012.

[46] M. S. Karambeigi, M. Nasiri, A. Haghighi Asl, and M. A. Emadi, "Enhanced oil recovery in high temperature carbonates using microemulsions formulated with a new hydrophobic component," Journal of Industrial and Engineering Chemistry, vol. 39, 2016.

[47] Z. Hu, E. Nourafkan, H. Gao, and D. Wen, "Microemulsions stabilized by in-situ synthesized nanoparticles for enhanced oil recovery," Fuel, vol. 210, 2017.

[48] G. F. D. Ferreira, D. R. Q. Souza, R. Lima, A. K. C. L. Lobato, A. C. M. Silva, and L. C. L. Santos, "Novel glycerin-based microemulsion formulation for enhanced oil recovery," Journal of Petroleum Science and Engineering, vol. 167, 2018.

[49] T. N. de Castro Dantas, A. C. de Oliveira, T. T. C. de Souza, C. R. dos Santos Lucas, E. de Andrade Araújo, and P. T. P. Aum, "Experimental study of the effects of acid microemulsion flooding to enhancement of oil recovery in carbonate reservoirs," Journal of Petroleum Exploration and Production Technology, vol. 10, 2020.

[50] W. Yang, J. Lu, B. Wei, H. Yu, and T. Liang, "Micromodel studies of surfactant flooding for enhanced oil recovery: a review," ACS Omega, vol. 6, no. 9, pp. 6064-6069, 2021.

[51] H. Amani, "Study of enhanced oil recovery by rhamnolipids in a homogeneous 2D micromodel," Journal of Petroleum Science and Engineering, vol. 128, 2015.

[52] M. Dong, Q. Liu, and A. Li, "Displacement mechanisms of enhanced heavy oil recovery by alkaline flooding in a micromodel," Particuology, vol. 10, 2012.

[53] G. Cheraghian, "An experimental study of surfactant polymer for enhanced heavy oil recovery using a glass micromodel by adding nanoclay," Petroleum Science and Technology, vol. 33, 2015.

[54] M. Mohajeri, M. Hemmati, and A. S. Shekarabi, "An experimental study on using a nanosurfactant in an EOR process of heavy oil in a fractured micromodel," Journal of Petroleum Science and Engineering, vol. 126, 2015.

[55] A. Mehranfar, M. H. Ghazanfari, M. Masihi, and D. Rashtchian, "Macroscopic and microscopic investigation of alkaline-surfactant-polymer flooding in heavy oil recovery using five-spot micromodels: the effect of shale geometry and connatewater saturation," Journal of Porous Media, vol. 18, 2015.

[56] A. Kianinejad, M. H. Ghazanfari, R. Kharrat, and D. Rashtchian, "An experimental investigation of surfactant flooding as a good candidate for enhancing oil recovery from fractured reservoirs using one-quarter five spot micromodels: the role of fracture geometrical properties," Energy Sources,
Part A: Recovery, Utilization, and Environmental Effects, vol. 35, 2013.

[57] E. Hadi, Experimental Investigation of Solvent Injection into Heavy Oil Layered Reservoirs Using Micromodel, Master's thesis, IFP School, Rueil-Malmaison, France, Petroleum University of Technology, Abadan, Iran, 2009.

[58] D. Green and G. Willhite, "Enhanced Oil Recovery," Functional Polymers, SPE, London, UK, 2nd edition, 2018. 